\title{
Effect of dutasteride on castration-resistant prostate cancer
}

\author{
TAKESHI AZUMA, YUKIHIDE MATAYOSHI, YUJIRO SATO and YASUHI NAGASE
}

Department of Urology, Tokyo Metropolitan Tama Medical Center, Fuchu, Tokyo 183-0042, Japan

Received April 21, 2017; Accepted October 30, 2017

DOI: $10.3892 / \mathrm{mco} .2017 .1480$

\begin{abstract}
It has previously been demonstrated that the intratumoral generation of the potent androgen dihydrotestosterone (DHT), contributes critically to the progression of prostate cancer and its castration-resistant form, castration-resistant prostate cancer (CRPC). Circulating testosterone is converted into DHT by $5 \alpha$-reductase (SRD5A). Dutasteride is a dual inhibitor of type I and II SRD5A. The present study assessed the effectiveness of dutasteride in the treatment of CRPC. Between 2010 and 2013, CRPC was diagnosed in 41 patients at the Tokyo Metropolitan Tama Medical Center. Following diagnosis, the patients received $0.5 \mathrm{mg}$ dutasteride daily. The patients' median age was 77.3 years (range, 63-90). Bone metastases were recognized in 12 patients. All the patients received dexamethasone. Twenty-four (59\%) patients had previously undergone chemotherapy, while 11 (27\%) received docetaxel, and $24(59 \%)$ estramustine. The prostatic-specific antigen (PSA) level declined in 17 (41\%) patients from the baseline value, following dutasteride treatment. The median value for the PSA decrease was $23 \%$ (range, 4.3-89.8\%), and the median duration of the response was 4 months (range, 1-10). The PSA response rate (defined as $>50 \%$ decline in PSA from the baseline value) was recognized in $7(17 \%)$ patients. The median duration of the response was 3 months (range, 2-10). Dutasteride was efficacious against CRPC in certain patients and may be a promising option in CRPC treatment. A prospective randomized trial is necessary to verify the efficacy of dutasteride.
\end{abstract}

\section{Introduction}

In most prostate cancer cases, androgen ablation is effective initially because the prostate cancer depends on androgens for growth (1). However, some of the cancers eventually recur, at which point they are termed 'castration-resistant prostate cancer (CRPC)' and can no longer be treated by conventional treatment (1). The mechanisms underlying this resistance were

Correspondence to: Dr Takeshi Azuma, Department of Urology, Tokyo Metropolitan Tama Medical Center, 2-9-2 Musashidai, Fuchu, Tokyo 183-0042, Japan

E-mail: tazuma-tky@umin.ac.jp

Key words: prostate cancer, dutasteride, castration-resistant prostate cancer thought to be androgen receptor amplification, gain-of-function mutation, and novel splice variant expression (2). However, recent studies have shown that CRPC development still depends on the intratumoral generation of the potent androgen, dihydrotestosterone (DHT) (3-5). Moreover, the androgen levels in the prostate tissue of CRPC patients are comparable with levels in healthy men (6-8), thus accounting for the continued expression of androgen-dependent genes after androgen ablation (9). These findings are consistent with the reportedly low number of complete clinical responses observed in a trial of neoadjuvant androgen deprivation therapy (10). However, the effectiveness of some next-generation, androgen-modulating drugs (enzalutamide and abiraterone acetate) has been reported (11-13).

Circulating testosterone is converted into DHT by $5 \alpha$-reductase (SRD5A). Three $5 \alpha$-reductase isoforms (SRD5A types I, II, and III) have been detected in the prostate (14). In normal prostate tissue, DHT was produced mainly by SRD5A. SRD5A type I is reportedly overexpressed in the primary and metastatic sites of CRPC patients and bypasses testosterone, using instead androstenedione as a substrate to produce $5 \alpha$-androstanedione, which is then converted to DHT (15). SRD5A type I is therefore thought to play a critical role in the progression of prostate cancer.

SRD5A inhibitors can inhibit the conversion of testosterone to DHT. Finasteride can selectively inhibit SRD5A type II to decrease the incidence of prostate cancer but lacks clear activity against CRPC. Dutasteride is a dual inhibitor of SRD5A types I and II and is reportedly effective in the treatment of benign prostatic hyperplasia and preventing prostate cancer $(16,17)$. However, its efficacy against CRPC is still unclear (18). In the present study, we assessed the efficacy of dutasteride against CRPC.

\section{Patients and methods}

Patients. Between 2010 and 2013, 41 patients at the Tokyo Metropolitan Tama Medical Center received the diagnosis of CRPC, which progressed despite the administration of luteinizing hormone-releasing hormone agonists, androgen receptor antagonist (flutamide or bicalutamide), or an orchiectomy.

The institutional review board of the Tokyo Metropolitan Tama Medical Center approved the study protocol. Each patient provided written informed consent.

Treatment. Dutasteride $0.5 \mathrm{mg} /$ day was given as additional treatment until the disease reached a progressive state. Luteinizing 
Table I. Characteristics of patients.

\begin{tabular}{lc}
\hline Variables & Average range \\
\hline Age, years & 77.3 \\
& $63-90$ \\
PSA at initiation of dutasteride, $\mathrm{ng} / \mathrm{ml}$ & 197.3 \\
& $17-1,297$ \\
\hline
\end{tabular}

Variables

No. of patients (\%)

Gleason score at diagnosis

$\begin{array}{lc}4-6 & 1(2) \\ 7 & 12(30) \\ 8-9 & 21(51) \\ \text { Unknown } & 7(17) \\ \text { Prior treatment } & \\ \text { Orchiectomy } & 12(29) \\ \text { LHRH agonist } & 29(71) \\ \text { Bicalutamide } & 41(100) \\ \text { Flutamide } & 41(100) \\ \text { Dexamethasone } & 41(100) \\ \text { Estramustine } & 24(59) \\ \text { Docetaxel } & 11(27) \\ \end{array}$

hormone-releasing hormone agonists and dexamethasone were continued after dutasteride administration. A partial response was defined as $\geq 2$ PSA values obtained at least four weeks apart exceeding $50 \%$ of the baseline value with no evidence of disease progression on imaging. A progressive disease was defined as a $25 \%$ increase in the serum PSA level over the last pre-registration measurement confirmable at least four weeks later. In patients showing a decrease in serum PSA levels during dutasteride administration, a progressive disease was defined as a confirmed increase of $25 \%$ to $\geq 5 \mathrm{ng} / \mathrm{ml}$ over the nadir (19).

Statistical analysis. The distribution of the recurrence-free survival (RFS) rate was constructed using the Kaplan-Meier method. Univariate and multivariable logistic regression were performed to assess clinicopathologic characteristics associated with PSA response. Statistical analyses were performed using the $\mathrm{JMP}^{\circledR}$ software package. $\mathrm{P}<0.05$ was considered statistically significant.

\section{Results}

Patient characteristics. The patient and disease characteristics are shown in Table I. The median age of the patients was 77.3 years (range, 63-90). Bone metastases were recognized in 12 patients. All patients received dexamethasone. Of $24(59 \%)$ patients who had previously undergone chemotherapy, $11(27 \%)$ patients had received docetaxel, and 24 (59\%) had received estramustine. The median follow-up period was 4.8 months with a range of 1.5-16.2 months.

The median progression-free survival was 3.7 months (Fig. 1). No significant adverse events were encountered.

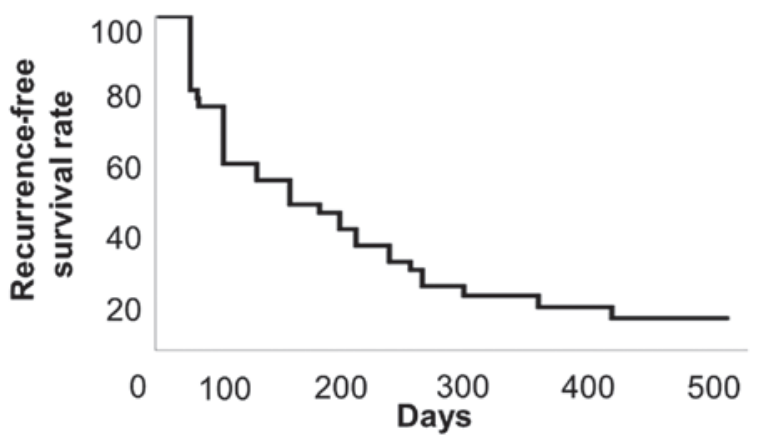

Figure 1. Kaplan-Meier analysis of recurrence-free survival.

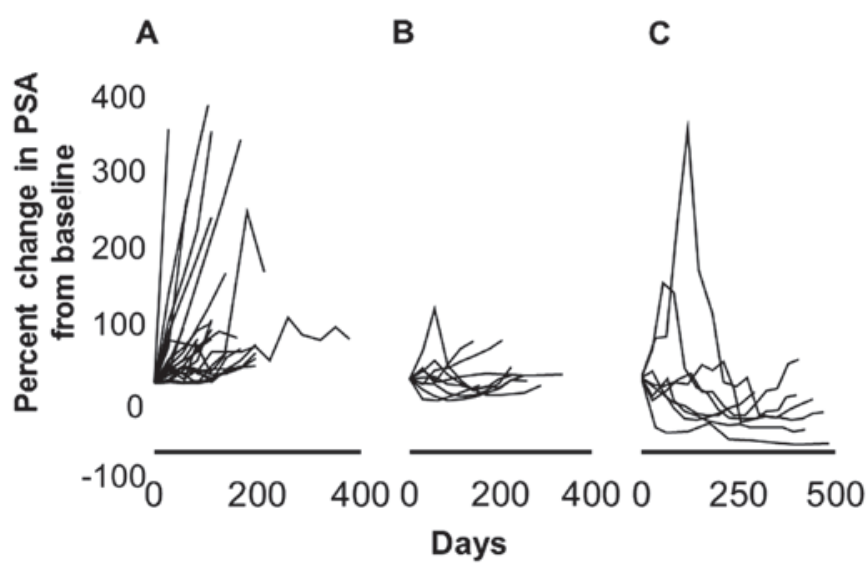

Figure 2. PSA kinetics after addition of dutasteride to treatment. (A) Kinetics of PSA in patients with progressive CRPC. (B) Patients with a $<50 \%$ decline in PSA values from the baseline. (C) Patients with a $>50 \%$ decline in PSA values from the baseline. PSA, prostatic-specific antigen; CRPC, castration-resistant prostate cancer.

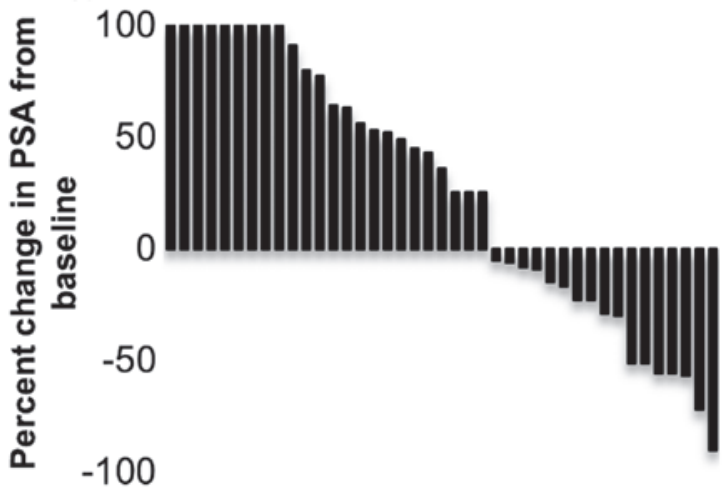

Figure 3. Maximal change in prostatic-specific antigen from the baseline.

PSA kinetics and maximal change. Fig. 2 shows the PSA kinetics during the administration of dutasteride. Fig. 3 shows the maximum decrease in PSA from the baseline for each patient. Seventeen $(41 \%)$ patients showed a decline in their PSA level from the baseline due to the administration of dutasteride. The median PSA decrease was 23\% (range, 4.3-89.8\%), and the median duration of response was four months (range, 1-10). The PSA response rate (defined as $>50 \%$ decline in PSA 
Table II. Univariable and multivariable logistic regression models to predict PSA response

\begin{tabular}{|c|c|c|c|c|}
\hline \multirow[b]{2}{*}{ Variables } & \multicolumn{2}{|c|}{ Univariate } & \multicolumn{2}{|c|}{ Multivariate } \\
\hline & OR $(95 \% \mathrm{CI})$ & P-value & OR $(95 \% \mathrm{CI})$ & P-value \\
\hline Age & $\begin{array}{c}1.12 \\
0.92-3.87\end{array}$ & 0.58 & & \\
\hline PSA at diagnosis & $\begin{array}{c}0.88 \\
0.69-2.81\end{array}$ & 0.072 & & \\
\hline $\begin{array}{l}\text { PSA at initiation } \\
\text { of dutasteride }\end{array}$ & $\begin{array}{c}0.75 \\
0.29-0.85\end{array}$ & 0.039 & $\begin{array}{c}0.67 \\
0.13-0.79\end{array}$ & 0.041 \\
\hline Time to CRPC & $\begin{array}{c}2.12 \\
0.81-3.01\end{array}$ & 0.71 & & \\
\hline $\begin{array}{l}\text { T stage } \\
\text { T1-2 vs T3-4 }\end{array}$ & $\begin{array}{c}0.84 \\
0.62-2.12\end{array}$ & 0.21 & & \\
\hline $\begin{array}{l}\text { N stage } \\
\text { N0 vs N1 }\end{array}$ & $\begin{array}{c}0.72 \\
0.52-0.91\end{array}$ & 0.042 & $\begin{array}{c}1.92 \\
0.67-2.31\end{array}$ & 0.31 \\
\hline $\begin{array}{l}\text { M stage } \\
\text { M0 vs M1 }\end{array}$ & $\begin{array}{c}0.62 \\
0.23-0.91\end{array}$ & 0.028 & $\begin{array}{c}0.94 \\
0.31-1.91\end{array}$ & 0.11 \\
\hline
\end{tabular}

PSA, prostate specific antigen; CRPC, castration resistant prostate cancer.

Table III. Response rate according to previous treatment.

\begin{tabular}{ll}
\hline Variables & No. of patients (\%) \\
\hline PSA response rate & $10(59)$ \\
Without chemotherapy (17) & \\
Any PSA decline from baseline & $4(31)$ \\
Estramustine (13) & $3(27)$ \\
Estramustine + Docetaxel (11) & \\
$>50 \%$ PSA decline from baseline & $5(29)$ \\
Without chemotherapy (17) & $2(15)$ \\
Estramustine (13) & $0(0)$ \\
Estramustine + Docetaxel (11) & \\
\hline
\end{tabular}

from baseline) was recognized in $7(17 \%)$ patients. The median duration of response was three months (range, 2-10). In three cases, PSA initially increased during therapy but decreased later to values below the baseline. A decrease in PSA was recognized three months and six months after dutasteride administration in one and six patients, respectively. No significant adverse effect was recognized.

Univariate logistic regression analysis was used to detect factors predicting PSA response (Table II). PSA at initiation of dutastereide, $\mathrm{N}$ stage and $\mathrm{M}$ stage were statistically significant predictors of $\mathrm{PCa}$ at biopsy $(\mathrm{P} \leq 0.05)$. In multivariate models, only PSA at initiation of dutastereide was an independent predictor for PSA resposnse (Table II).

Table III shows the PSA response rates in prior treatments. PSA decreased in three patients after treatment with docetaxel (27\%). However, with $\leq 50 \%$ decrease in PSA, the response rate was lower than in patients who did not receive docetaxel.

\section{Discussion}

Dutasteride is known to be effective in preventing prostate cancer and treating low-risk prostate cancer. However, the role of SRD5A inhibitors in the progression of prostate cancer to CRPC has not been well studied (18). The development of CRPC is still dependent on DHT, and some next-generation drugs targeting the androgen signaling pathway were reportedly effective (11-13). We therefore assessed the effects of dutasteride in patients with CRPC by assessing changes in PSA levels.

The present study showed that $41 \%$ of patients with progressive CRPC showed a decrease in their PSA level, with $17 \%$ showing a decrease greater than $50 \%$. The median duration of the PSA response was four months.

The mainstay of treatment for CRPC patients is chemotherapy. However, in some cases chemotherapy cannot be performed due to performance status, age, adverse effects, or complications. For these patients the only recourse has thus far only been palliative care. Our results show that there may be another treatment option available.

Notably, 8 (47\%) of 17 patients exhibiting any response showed an initial increase followed by a decrease in their serum PSA level. The reason for the initial increase in PSA level is unclear. One possibility is that dutasteride required several months to produce its effects, a possibility made more likely by the fact that the drug requires about six months to shrink benign prostate hyperplasia. Another possibility is that dutasteride treatment caused a surge in PSA like that seen in chemotherapy (20). These results suggest that dutasteride 
should be continued for at least three months, even when the serum PSA level increases.

The present study has some limitations inherent in a retrospective analysis. The prospective evaluation of the objective response on imaging, the symptomatic response, and toxicity, was not performed. It is possible that the impact of dutasteride on PSA endpoints may not translate into a worthwhile therapeutic effect on clinically meaningful endpoints. Prospective clinical studies are required to test this possibility.

Of note, the PSA response was recognized in three CRPC patients after chemotherapy using docetaxel. In two patients, a PSA decrease from baseline continued for more than six months. A study by Sartor did not include chemotherapy-resistant CRPC patients (21). While such patients do have some treatment options, controlling docetaxel-resistant CRPC remains difficult. These findings suggested that dutasteride may provide a promising option in the treatment of CRCP.

In summary, dutasteride was demonstrably effective in some CRPC cases and may be a promising therapeutic option for patients with CRPC. Prospective randomized trials are necessary to confirm the efficacy of dutasteride.

\section{References}

1. Marech I, Vacca A, Ranieri G, Gnoni A and Dammacco F: Novel strategies in the treatment of castration-resistant prostate cancer (Review). Int J Oncol 40: 1313-1320, 2012.

2. Nacusi LP and Tindall DJ: Targeting $5 \alpha$-reductase for prostate cancer prevention and treatment. Nat Rev Urol 8: 378-384, 2011.

3. Locke JA, Guns ES, Lubik AA, Adomat HH, Hendy SC, Wood CA, Ettinger SL, Gleave ME and Nelson CC: Androgen levels increase by intratumoral de novo steroidogenesis during progression of castration-resistant prostate cancer. Cancer Res 68: 6407-6415, 2008.

4. Montgomery RB, Mostaghel EA, Vessella R, Hess DL, Kalhorn TF, Higano CS, True LD and Nelson PS: Maintenance of intratumoral androgens in metastatic prostate cancer: A mechanism for castration-resistant tumor growth. Cancer Res 68 4447-4454, 2008.

5. Stanbrough M, Bubley GJ, Ross K, Golub TR, Rubin MA, Penning TM, Febbo PG and Balk SP: Increased expression of genes converting adrenal androgens to testosterone in androgen-independent prostate cancer. Cancer Res 66: 2815-2825, 2006.

6. Geller J, Albert JD, Nachtsheim DA and Loza D: Comparison of prostatic cancer tissue dihydrotestosterone levels at the time of relapse following orchiectomy or estrogen therapy. J Urol 132: 693-696, 1984.
7. Mohler JL, Gregory CW, Ford OH III, Kim D, Weaver CM, Petrusz P, Wilson EM and French FS: The androgen axis in recurrent prostate cancer. Clin Cancer Res 10: 440-448, 2004.

8. Titus MA, Schell MJ, Lih FB, Tomer KB and Mohler JL: Testosterone and dihydrotestosterone tissue levels in recurrent prostate cancer. Clin Cancer Res 11: 4653-4657, 2005.

9. Mostaghel EA, Page ST, Lin DW, Fazli L, Coleman IM, True LD, Knudsen B, Hess DL, Nelson CC, Matsumoto AM, et al: Intraprostatic androgens and androgen-regulated gene expression persist after testosterone suppression: Therapeutic implications for castration-resistant prostate cancer. Cancer Res 67: 5033-5041, 2007.

10. Gleave ME, La Bianca S and Goldenberg SL: Neoadjuvant hormonal therapy prior to radical prostatectomy: Promises and pitfalls. Prostate Cancer Prostatic Dis 3: 136-144, 2000.

11. Ryan CJ, Smith MR, de Bono JS, Molina A, Logothetis CJ, de Souza P, Fizazi K, Mainwaring P, Piulats JM, Ng S, et al: Abiraterone in metastatic prostate cancer without previous chemotherapy. N Engl J Med 368: 138-148, 2013.

12. Scher HI, Fizazi K, Saad F, Taplin ME, Sternberg CN, Miller K, de Wit R, Mulders P, Chi KN, Shore ND, et al: Increased survival with enzalutamide in prostate cancer after chemotherapy. $\mathrm{N}$ Engl J Med 367: 1187-1197, 2012.

13. Yin L and Hu Q: CYP17 inhibitors-abiraterone, C17,20-lyase inhibitors and multi-targeting agents. Nat Rev Urol 11: 32-42, 2014.

14. Uemura M, Tamura K, Chung S, Honma S, Okuyama A, Nakamura $Y$ and Nakagawa H: Novel 5 alpha-steroid reductase (SRD5A3, type-3) is overexpressed in hormone-refractory prostate cancer. Cancer Sci 99: 81-86, 2008.

15. Chang KH, Li R, Papari-Zareei M, Watumull L, Zhao YD, Auchus RJ and Sharifi N: Dihydrotestosterone synthesis bypasses testosterone to drive castration-resistant prostate cancer. Proc Natl Acad Sci USA 108: 13728-13733, 2011.

16. Andriole GL, Bostwick DG, Brawley OW, Gomella LG, Marberger M, Montorsi F, Pettaway CA, Tammela TL, Teloken C, Tindall DJ, et al: Effect of dutasteride on the risk of prostate cancer. N Engl J Med 362: 1192-1202, 2010.

17. Barkin J, Guimaraes M, Jacobi G, Pushkar D, Taylor S and van Vierssen Trip OB: Alpha-blocker therapy can be withdrawn in the majority of men following initial combination therapy with the dual 5alpha-reductase inhibitor dutasteride. Eur Urol 44: 461-466, 2003.

18. Tindall DJ and Rittmaster RS: The rationale for inhibiting 5alpha-reductase isoenzymes in the prevention and treatment of prostate cancer. J Urol 179: 1235-1242, 2008.

19. Petrylak DP, Macarthur RB, O'Connor J, Shelton G, Judge T, Balog J, Pfaff C, Bagiella E, Heitjan D, Fine R, et al: Phase I trial of docetaxel with estramustine in androgen-independent prostate cancer. J Clin Oncol 17: 958-967, 1999.

20. Sella A, Sternberg CN, Skoneczna I and Kovel S: Prostate-specific antigen flare phenomenon with docetaxel-based chemotherapy in patients with androgen-independent prostate cancer. BJU Int 102: 1607-1609, 2008 .

21. Sartor O, Nakabayashi M, Taplin ME, Ross RW, Kantoff PW, Balk SP and Oh WK: Activity of dutasteride plus ketoconazole in castration-refractory prostate cancer after progression on ketoconazole alone. Clin Genitourin Cancer 7: E90-E92, 2009. 